\title{
Extrusion Pressure Generated in High Alumina Content Paste Extrusion
}

\author{
X.P.Chi ${ }^{1}$, S.Yang ${ }^{2 *}$, J.R.G.Evans ${ }^{3}$ \\ 1. Department of Materials, Queen Mary, University of London, Mile End Road, London, E14 NS, UK. \\ 2. School of Engineering Science, University of Southampton \\ Southampton, SO17, 1BJ, UK \\ 3. Department of Chemistry, University College London, \\ 20 Gordon Street, London, WC1H 0AJ, UK. \\ *email: s.yang@soton.ac.uk
}

\begin{abstract}
Four different alumina pastes with various solvent volume fractions were processed by extrusion freeforming and the pressures generated in the extrusion process were recorded and analyzed. The extrusion pressure increased as the solvent volume fraction decreased. Air bubbles and particle agglomeration influenced the final properties of the product and caused pressure to fluctuate. An aging process for the paste was introduced to obtain more even solvent distribution and hence deliver highly regular ceramic lattice structures.
\end{abstract}

Keywords-extrusion pressure, alumina paste, extrusion freeforming, Computer-aided manufacturing

\section{INTRODUCTION}

Several rapid prototyping (RP) methods have been applied to fabricate ceramic components directly. These methods include extrusion freeforming which is derived from fused deposition modeling of polymers.

In extrusion freeforming, an applied pressure is used to press the paste into the die entry and the die-land regions. Akdogan [1] pointed out that once the pressure drops along the die have been determined, estimation of the flow characteristics of the paste is possible. Understanding the nature of the flow in dies is helpful to control extruder performance and extrudate quality. Inadequate control of extrusion pressure causes flaws in the extrudate such as surface fracture and delamination. So extrusion pressure is an important factor for monitoring the extrusion process.

Benbow and Bridgwater [2] demonstrated that the total extrusion pressure $(\mathrm{P})$ to press particulate pastes comprising fine particles suspended in a continuous liquid phase, through dies with circular cross section and having a square entry (shown in Figure 1), can be described by the following equation:

$$
p=p_{e}+p_{1}=2\left(\sigma_{0}+\alpha V^{n}\right) \ln \left[D_{0} / D\right]+4\left(\tau_{0}+\beta V^{m}\right)[L / D]
$$

where $p$ is the total extrusion pressure, $p_{e}$ is the die entry pressure, $p_{1}$ is die land pressure, $\alpha$ is a velocity-dependent factor for convergent flow, $\beta$ is the velocity-dependent factor for parallel flow, $n$ and $m$ are exponents, $\sigma_{0}$ is the paste bulk yield value, $\tau_{0}$ is the paste characteristic initial wall shear stress, $D_{0}$ and $D$ are the diameters of the barrel and of the die respectively, $L$ is the die-land length and $V$ is the extrudate velocity. In this equation, die-entry $\left(p_{e}\right)$ and die-land $\left(p_{1}\right)$ pressures are separated.

A coefficient of static friction for the extrudate $(\mu)$ has been demonstrated to be another relevant parameter in defining extrusion issues and the ultimate surface quality of samples [3] and can be calculated by the following relationship:

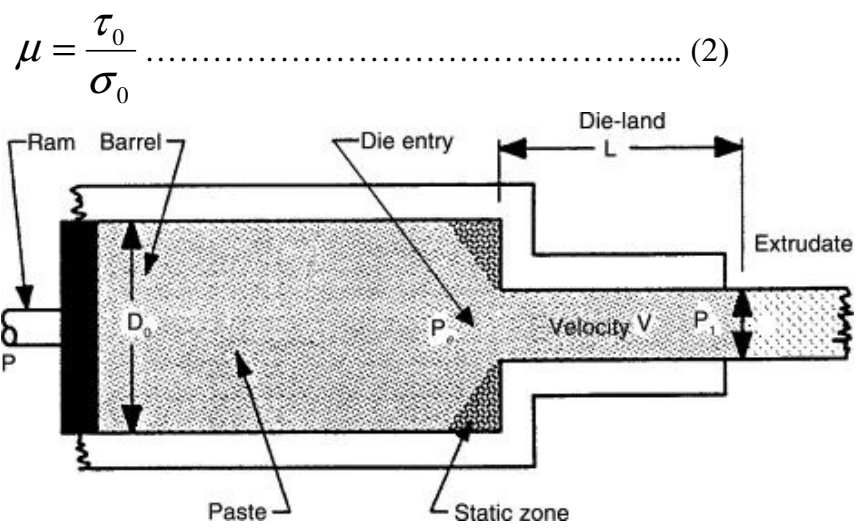

Figure 1. Schematic view of extrusion through a square die in a ram extruder.

For highly concentrated solid-liquid suspensions or pastes, particularly as the solids volume fraction exceeds $50 \%$ and approaches the maximum packing fraction, particle-particle interactions and the use of non-Newtonian liquids result in these materials exhibiting non-Newtonian behaviour. Extrusion features such as wall slip and yield stress behaviour are frequently reported.

A typical pressure transient (Figure 2) during PTFE paste extrusion in the capillary rheometer was reported by Ochoa and Hatzikiriakos[4]. The whole pressure curve has been divided into three zones. The pressure gradually increases and goes through a maximum in zone I and then presents a steady state in zone II. Finally, the extrusion pressure gradually increases again in zone III. In previous work [2, 5-7], the pressure peak appearing in zone I has contributed to the initial filling and wetting of the conical zone of the die. But Ariawan et al. [8] 
demonstrated that the pressure peak still appeared when the conical zone was filled before extrusion. For visco-elastoplastic materials, Ochoa and Hatzikiriakos [4] attribute the pressure peak to the yield stress and to particles initially jamming.

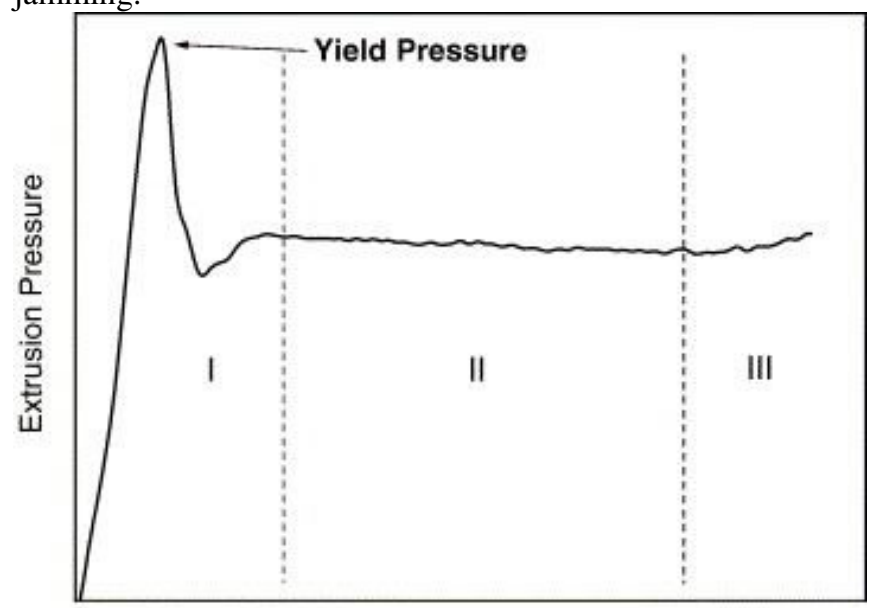

Distance in the barrel

Figure 2. Typical behaviour of a pressure transient during PTFE paste extrusion[4]. (reproduced by kind permission of Powder Technology)

As shown in Figure 3, when the extrusion was stopped and restarted after short relaxation times, the pressure to initiate paste flow was very small compared to the initial maximum pressure. But after a long relaxation time, the immobile clusters of particles had been reinstated and the maximum pressure was equal to the initial maximum pressure. The gradual increase of the extrusion pressure in zone III is because the solvent evaporation during the extrusion process caused the final part of the paste to become drier.

Extrusion fluctuation can be induced by defects in the paste like entrapped gas or agglomerates. It has previously been reported [9] that uniform pastes with minimum defects can be obtained when the paste is pressed at $2 \mathrm{MPa}$ for $30 \mathrm{~s}$ at $35^{\circ} \mathrm{C}$.

In this experiment, we demonstrate that the distinct extrusion system used has different friction between plunger and syringe wall which can contribute pressures much higher than the die-entry pressure $\left(p_{e}\right)$ and die-land $\left(p_{1}\right)$ pressure in equation (1). This is because the extrusion barrel is much smaller than those used in traditional paste extrusion so the friction between plunger and syringe wall cannot be neglected.

We recorded pressure traces during extrusion freeforming and sought to interpret the information they provide to serve as a real-time process monitor.

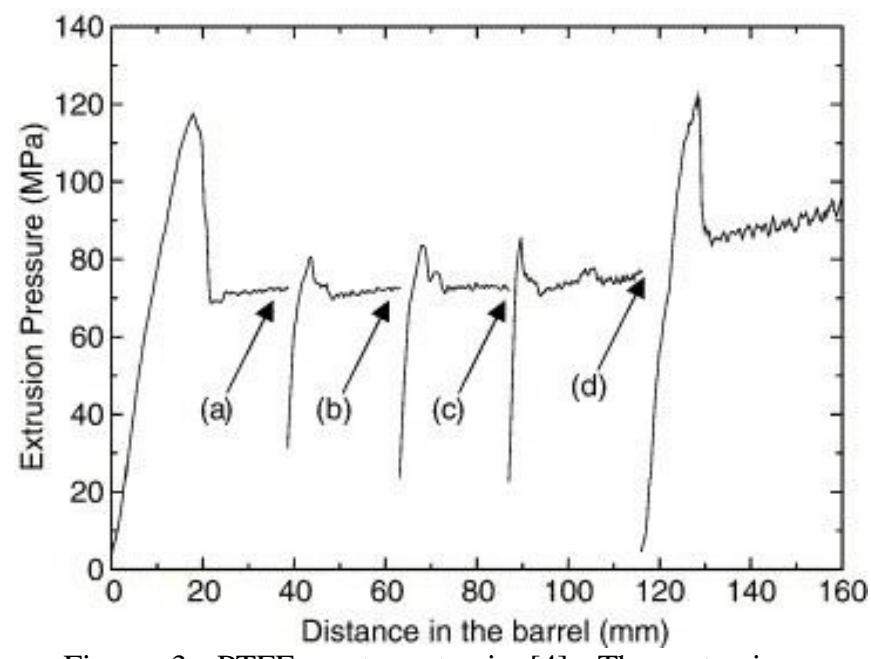

Figure 3. PTFE paste extrusion[4]. The extrusion was stopped and restarted after (a) $1.5 \mathrm{~min}$. (b) $10 \mathrm{~min}$. (c) $45 \mathrm{~min}$. (d) $40 \mathrm{~h}$. (reproduced by kind permission of Powder Technology)

\section{EXPERIMENTAL DetaILS}

The alumina powder $\left(\mathrm{Al}_{2} \mathrm{O}_{3}\right.$, HPA-0.5 Condea Vista, USA) used in this experiment, has a purity of $99.992 \%$, surface area of $10 \mathrm{~m}^{2} \mathrm{~g}^{-1}$, typical particle size of $0.48 \mu \mathrm{m}$ and density of $3960 \mathrm{kgm}^{-3}$. Poly(vinyl butyral) (PVB, Grade BN18, Wacker Chemicals, UK) with density of $1100 \mathrm{kgm}^{-3}$ was used as the binder with additions of a grade of poly(ethylene glycol) (PEG, MWt $=600$, VWR, UK) which is a liquid at ambient temperature and has a density of $1127 \mathrm{kgm}^{-3}$. Propan-2-ol (GPR, VWR, UK) with density of $789 \mathrm{kgm}^{-3}$ was used as solvent.

The alumina paste was prepared as follows. The PVB and the PEG were fully dissolved in propan-2-ol in proportions 75 wt.\% PVB - 25 wt.\% PEG. Alumina powder was added to provide a ceramic/polymer mixture with 60 vol. $\%$ of ceramic based on the dry mass and stirred on a hotplate. An ultrasonic probe (IKA U200S, IKA Labortechnik Staufen, Germany) was used to disrupt agglomerates and enhance dispersion. To prevent the suspension from sedimenting, the suspension was poured into plastic bottles and was agitated on a roller mixer. The suspension was then concentrated on the hot-plate with magnetic stirrers to develop a suitable paste for extrusion.

The method of state change used here results from a decrease of solvent content [10]. The paste composed of ceramic, polymer and solvent has a high yield stress but is able to weld to the previous layer before solidifying by solvent evaporation. The non-volatiles (ceramic + polymer) constitute typically $70-80$ vol. \% of the mixture and $20-30$ vol. \% is volatile solvent (usually propan-2-ol). The drying-induced shrinkage after assembly was minimized to reduce distortion of the lattice.

A schematic diagram of the extrusion freeforming worktable is shown in Fig. 4. The paste was extruded into filaments from an extruder (Figure 4. a) by a lead screw (Figure $4 \mathrm{c}, 1 \mathrm{~mm}$ pitch ball screws, Automation Ltd., Oldham, UK) 
driven by a stepper motor $(50,000$ steps/rev, supplied by ACP\&D Ltd., Ashton-under-Lyne, UK) with gear box (Figure 4 d, 64-1 reduction box). A load cell (Figure 4 b, Flintec Ltd., Redditch, UK) was used to record the pressure and provide the over-load alarm. The filaments were assembled into different structures by moving the substrate which was controlled by the $\mathrm{X}$ and $\mathrm{Y}$ table axes, to give a series of 2D samples. The threeaxis table comprises linear servo motors (MX80L Miniature Stage, Parker Hannifin Automation, Poole, Dorset, UK) driving the $\mathrm{X}, \mathrm{Y}$ table axes and stepper motors driving the $\mathrm{Z}$ axis (Figure 5.). This high performance linear servo motor table is capable of high acceleration $\left(49 \mathrm{~ms}^{-2}\right)$, speed $\left(3 \mathrm{~ms}^{-1}\right)$ and encoder resolution to $0.1 \mu \mathrm{m}$. To get a $3 \mathrm{D}$ sample, the $\mathrm{Z}$ axis (Figure 4 e) driven by a stepper motor (Figure $4 \mathrm{f}$, supplied by ACP\&D Ltd., Ashton-under-Lyne, UK) was used to control the vertical movement of the whole press axis. In this way, a 3D sample can be made layer by layer. To control the $\mathrm{Z}$ axis accurately, a proximately sensor (Figure $4 \mathrm{~h}$ ) was used.

Only four motion controllers were used. One was used to control the $\mathrm{Z}$ axis; another two were used to control the $\mathrm{X}, \mathrm{Y}$ table axes separately. The last motion controller was used for both lead screws to extrude the paste, their relative speeds adjusted by a frequency divider (Figure $4 \mathrm{~g}$ ). These four motion controllers were addressed by a computer through LabVIEW software. The extrusion freeforming equipment is shown in Figure 5.

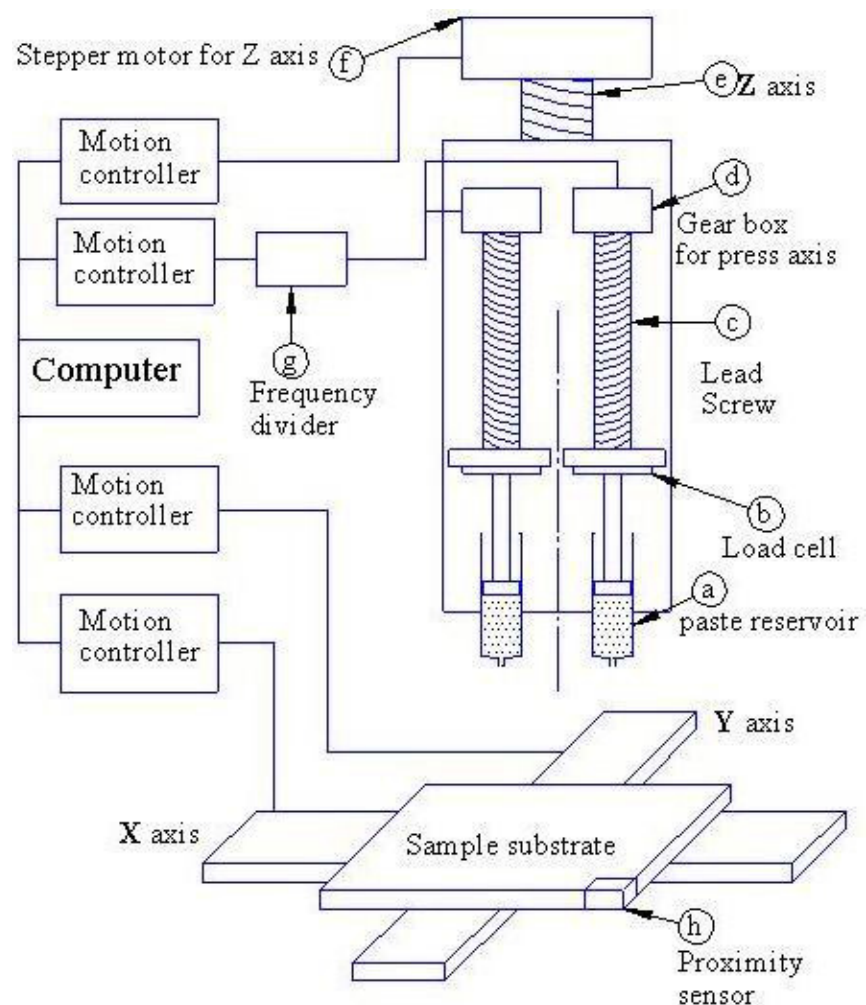

Figure 4. Schematic of the extrusion freeforming worktable.

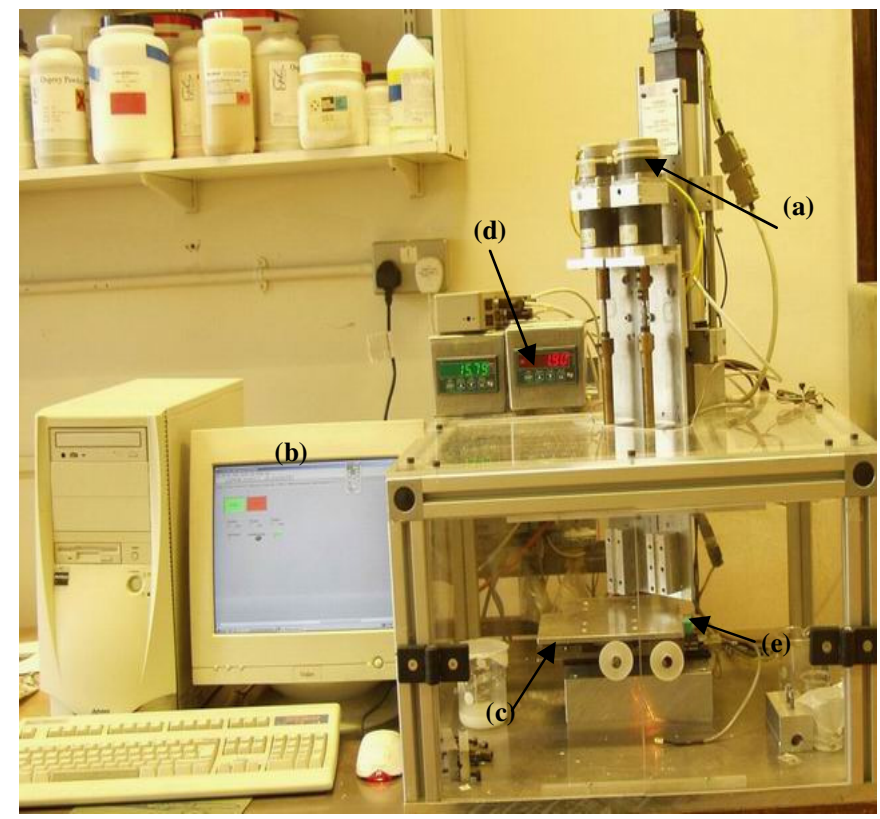

Figure 5. Extrusion freeforming apparatus, (a) microstepper motors, (b) operating system, (c) linear motor XY table, (d) load cell meters, (e) the proximately sensor.

Hypodermic syringes (HGB81320 1ml, Hamilton GB, Ltd., Carnforth, U.K.) were used as extrusion cylinders, plungers and nozzle.

\section{RESULTS AND DISCUSSION}

TABLE 1

SOLVENT VOLUME FRACTIONS OF PASTES.

\begin{tabular}{lcc}
\hline & $\begin{array}{l}\text { Solvent content in the paste } \\
\text { close to the die /vol. } \%\end{array}$ & \multicolumn{2}{c}{$\begin{array}{l}\text { Solvent content in the paste } \\
\text { close to the extrusion ram } \\
\text { /vol.\% }\end{array}$} \\
\hline Paste A & 42 & 30 \\
Paste B & 35 & 30 \\
Paste C & 31 & 29 \\
Paste D & 32 & 29 \\
& 31 & 29 \\
\hline
\end{tabular}

The in-situ solvent volume fractions of five alumina-based pastes were measured and are shown in Table 1. It took 3-4 minutes to charge the syringe, which resulted in differential solvent evaporation; solvent volume fraction close to the die being greater than that close to the extrusion ram. This difference in solvent volume fraction was much greater in the case of pastes A and B which were loaded into the syringe and extruded separately without delay. Pastes C, D and E were loaded into syringes separately and then left in a sealed container with propan-2-ol vapour for $24 \mathrm{~h}$ before extrusion. This ageing process resulted in more even solvent distribution within the paste.

The pressure transient during extrusion of paste $A$ is recorded in Figure 6. The curve has been divided into five 
zones. The extrusion distance (between die exit and substrate) was $200 \mu \mathrm{m}$ in zones I, III and V. In zones II and IV, the substrate was removed and the extrudate flowed freely. In these zones, extrusion pressure decreased. Thus the substrate induces a back pressure which disappears when the substrate is taken away. From Figure 6, a noisy pressure trace is seen in zone I but this disappeared in other zones. Pressure 'noise' indicates that the paste was not homogeneous; defects, such as entrapped gas and voids are present[11]. It has been reported that the paste can be homogenized when a pressure of $2 \mathrm{MPa}$ is applied to it and, at the same time, the entrapped gas and voids can be removed[4]. Pressure fluctuated regularly in extrusion for all pastes. The mean time between two wave peaks was $120 \mathrm{~s}$. The distance traveled in a single revolution by the ball screw used to drive the extrusion ram in this experiment was $1 \mathrm{~mm}$. The velocity of the extrusion was $0.00825 \mathrm{~mm} / \mathrm{s}$. So the time in which the ball screw traveled in a single revolution was approximately $120 \mathrm{~s}$ and pressure fluctuation was induced by rotation.

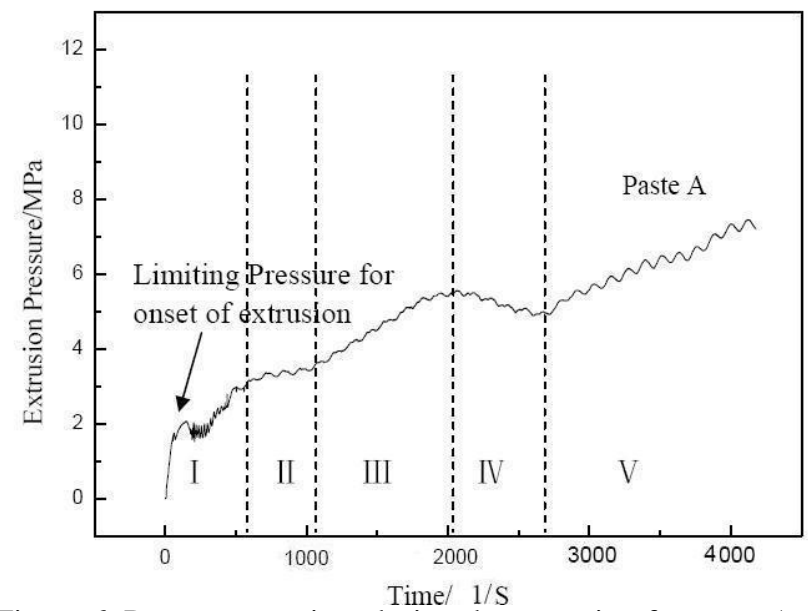

Figure 6. Pressure transient during the extrusion for paste $A$.

The initial pressure transients for extrusion of pastes B and $\mathrm{C}$ are seen in Figure 7. Initial pressure 'noise' did not appear in these two pressure transients which were extruded at about 2 $\mathrm{MPa}$ for several minutes before starting the experiment. Comparing the pressure traces for extrusion of pastes $\mathrm{B}$ and $\mathrm{C}$, the pressure increase is due to the solvent volume fraction nonuniformity along the barrel as shown in Table 1. This is to be distinguished from the consequence of dilatancy in which the vehicle moves through the assembly of particles [4] resulting in lower polymer concentration in the final part of the paste. Paste $\mathrm{C}$ had been left to age in a sealed container with propan-2-ol vapour for $24 \mathrm{~h}$ before extrusion.

An initial extrusion pressure peak (defined as limiting pressure for onset of extrusion in Figures 6 and 7) was obtained during the extrusion of Pastes A, B and C. Some authors attribute this pressure to the initial filling and wetting of the conical zone of the die [2, 5-7] but in the extrusion of pastes B and $\mathrm{C}$, it was present even though the conical zone of the die had been filled before extrusion. So the initial filling and wetting of the conical zone of the die was not the reason for this pressure, confirming a conclusion of Ariawan et al. [8].
Pastes with solid volume fraction exceeding 50\% typically exhibit non-Newtonian behaviour [12] and the initial wall stress [13] and yield stress [8] develop early in the paste extrusion process. The first pressure peak is partially attributed to finite compressibility [4]. Because the diameter of the die is smaller than that of the syringe (paste reservoir), the paste is compressed in the syringe before the limiting pressure for onset of extrusion is reached. This is demonstrated by Ochoa and Hatzikiriakos' result[4] as shown in Figure 3.

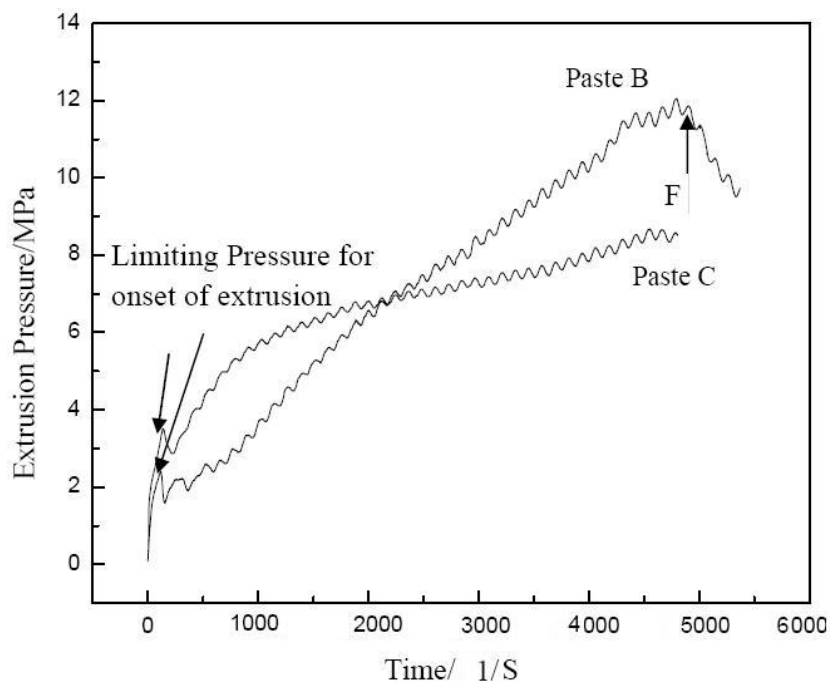

Figure 7. Pressure transient during the extrusion for pastes $\mathrm{B}$ and C. (arrow $\mathrm{F}$ indicates point at which substrate was removed)

Since a gas-tight syringe was used as the ram and barrel, friction at the syringe wall affects extrusion pressure as shown in Figure 8. The onset pressure of paste $\mathrm{E}$ is much higher than that of paste $\mathrm{D}$ due to two different syringes with different frictional contributions were used. The plunger in the syringe used for paste $\mathrm{E}$ is tighter than the one for paste D. A large number of parameters for each system must be collected in order to apply equation 1 . In this experiment, the extrusion pressure was recorded from the load cell on the ram. The extrusion pressure $P_{a}$ can be described by:

$$
p_{a}=p_{1}+p_{2}+f / s
$$

where $\mathrm{f}$ is the friction between the plunger and the syringe wall and $s$ is the contact area between plunger and syringe wall which is a constant as shown in Figure 4 (a). Figure 8 indicates that the friction between the plunger and the syringe used to extrude paste $\mathrm{E}$ is greater than that of the syringe used to extrude paste D. In this experiment, before automated extrusion, pastes D and E were extruded by hand from the die land, resulting in disappearance of the pressure for onset of extrusion. 


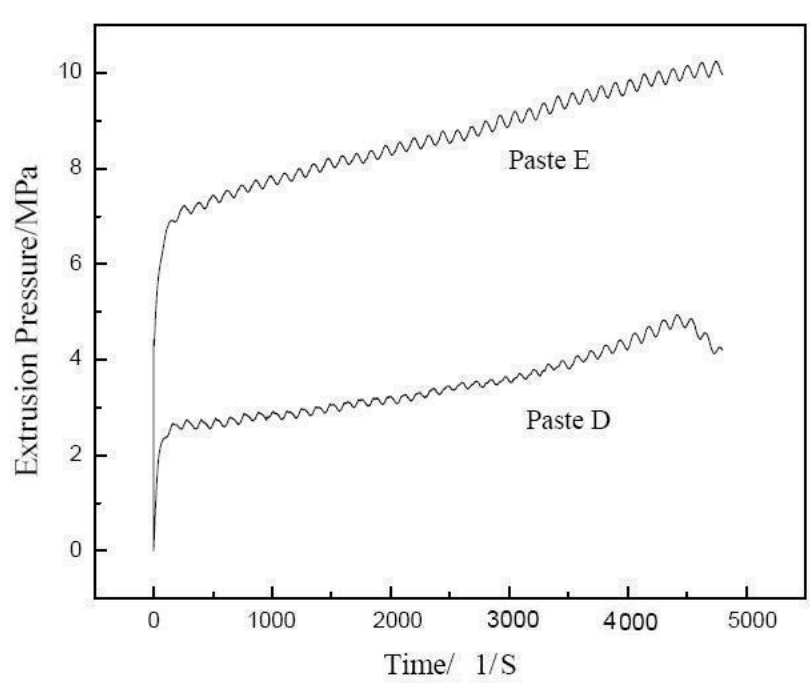

Figure 8. Pressure transient during extrusion of pastes D and $\mathrm{E}$.

The steady pressure gradients in Figure 8 are due to the slight solvent gradient from nozzle to plunger shown in Table 1.

Using this extrusion freeforming method, a wide range of 2-dimensional patterns can be assembled from which 3dimensional structures can be obtained. Figure 9 shows unsintered alumina lattices comprising 20 layers prepared from a paste with 26 vol. \% solvent, having an inter-filament distance of $630 \mu \mathrm{m}$. Figure 10 shows the regularity of a sintered alumina lattice in which the top layer has been polished to show intermittent extrusion defects. These structures can find applications in hard tissue scaffolds [14]and electromagnetic bandgap materials [15-17]

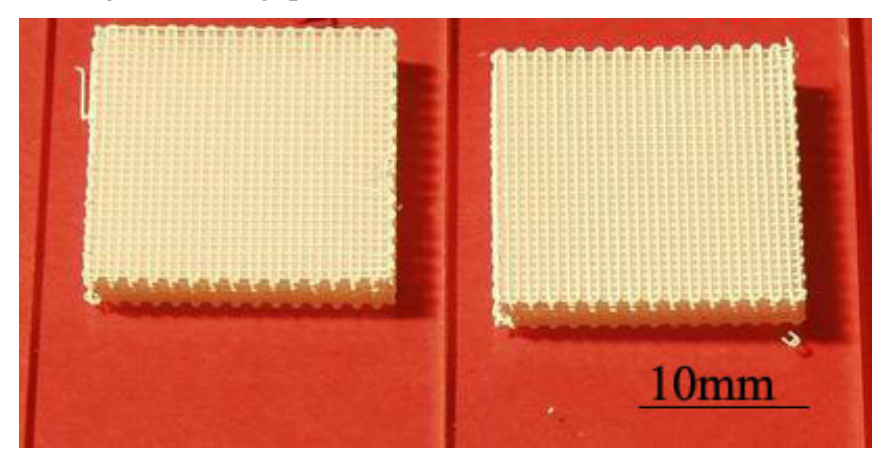

Figure 9. Unsintered alumina lattices comprising 20 layers prepared from a paste with 26 vol. \% solvent, having an interfilament distance of $630 \mu \mathrm{m}$.

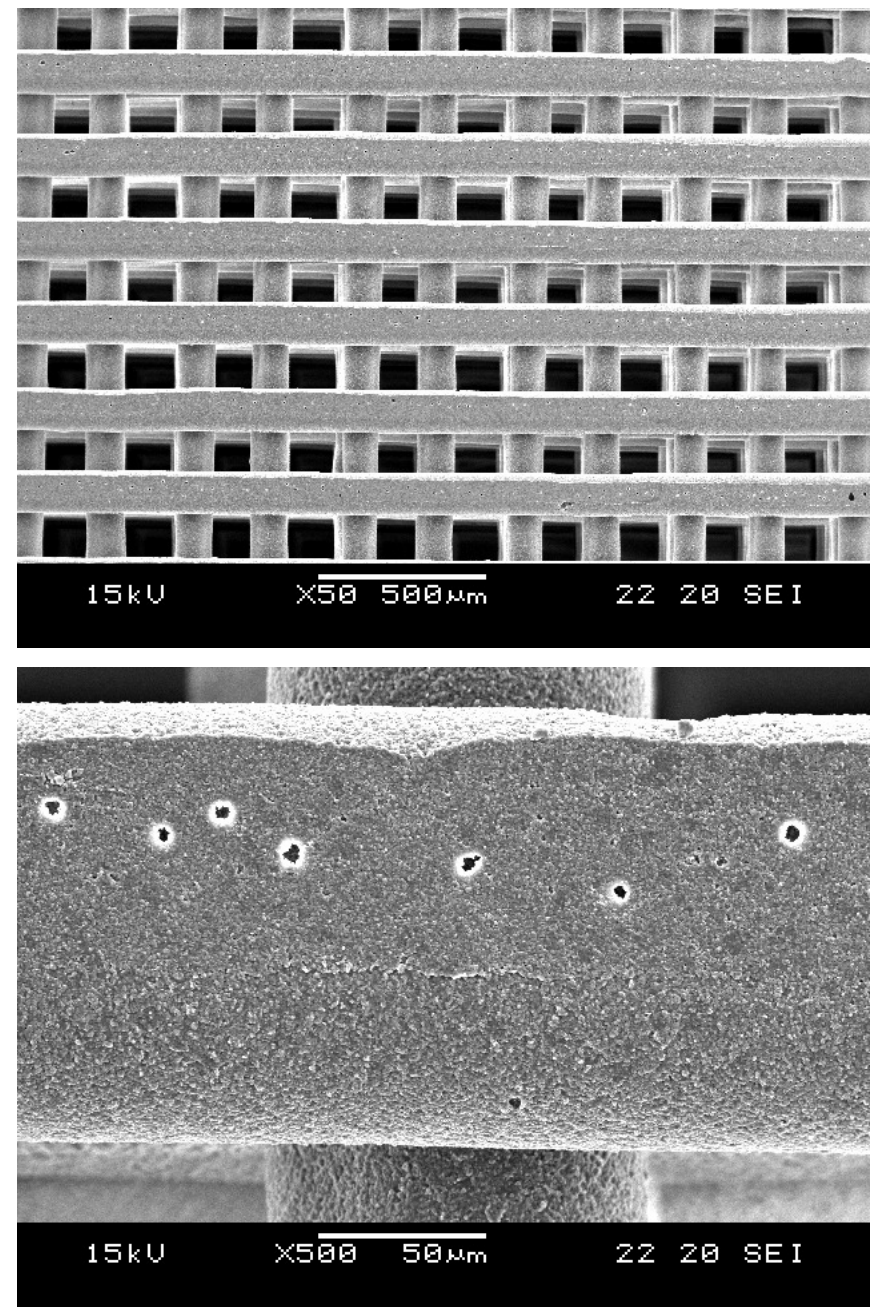

Figure 10. (a) Regular 3-D alumina lattice structure polished to show 3-4 $\mu \mathrm{m}$ extrusion defects.

\section{CONCLUSIONS}

In the extrusion freeforming of alumina pastes, extrusion pressure can fluctuate for a wide variety of reasons. Systematic but non-uniform distribution of solvent resulting from filling the extrusion chamber caused a steady increase in pressure as a function of ram movement. An initial pressure transient was attributed to relaxation effects in the paste. Regular pressure modulation during extrusion was attributed to the drive mechanism. The proximity of the building platform also produced a back pressure detected on the transducer. An ageing process resulted in more even solvent distribution within the paste and made it possibly to deliver regular lattice structures which have applications in hard tissue scaffolds and in millimeter wave photonics.

\section{ACKNOWLEDGMENTS}

The authors are grateful to the Engineering and Physical Sciences Research Council (EPSRC) for supporting this work under grant numbers GR/S57068 and GR/S52636. 


\section{REFERENCES}

1. Akdogan, H., Pressure, torque, and energy responses of a twin screw extruder at high moisture contents. Food Research International, 1996. 29(5-6): p. 423-429.

2. Benbow, J.J., E.W. Oxley, and J. Bridgwater, The Extrusion Mechanics of Pastes - the Influence of Paste Formulation on Extrusion Parameters. Chemical Engineering Science, 1987. 42(9): p. 2151-2162.

3. Ribeiro, M.J., et al., Extrusion of alumina and cordieritebased tubes containing Al-rich anodising sludge Journal of the European Ceramic Society, 2006. 26(4-5): p. 817-823.

4. Ochoa, I. and S.G. Hatzikiriakos, Paste extrusion of polytetrafluoroethylene (PTFE): Surface tension and viscosity effects. Powder Technology, 2005. 153(2): p. 108118.

5. Mazur, S., Paste Extrusion of Poly (tetrafluoroethylene) Fine Powders. Polymer Powder Technology. 1995, New York: John Wiley and Sons. 441-481.

6. Ariawan, A.B., S. Ebnesajjad, and S.G. Hatzikiriakos, Preforming behavior of polytetrafluoroethylene paste. Powder Technology, 2001. 121(2-3): p. 249-258.

7. Ariawan, A.B., S. Ebnesajjad, and S.G. Hatzikiriakos, Paste extrusion of polytetrafluoroethylene (PTFE) fine powder resins. Canadian Journal of Chemical Engineering, 2002. 80(6): p. 1153-1165.

8. Ariawan, A.B., S. Ebnesajjad, and S.G. Hatzikiriakos, Properties of polytetrafluoroethylene (PTFE) paste extrudates. Polymer Engineering and Science, 2002. 42(6): p. 1247-1259.

9. Ochoa, I. and S.G. Hatzikiriakos, Polytetrafluoroethylene paste preforming: viscosity and surface tension effects. Powder Technology, 2004. 146(1-2): p. 73-83.

10. Yang, S.F., et al., Rapid prototyping of ceramic lattices for hard tissue scaffolds. Materials \& Design, 2008. 29(9): p. 1802-1809.

11. Russell, B.D., et al., Characterising paste extrusion behaviour by signal processing of pressure sensor data. Powder Technology, 2003. 132(2-3): p. 233-248.

12. Ring, T.A., Fundamentals of Ceramic Powder Processing and Synthesis. 1996, San. Diego: Academic Press Inc. 3132.

13. Khan, A.U., B.J. Briscoe, and P.F. Luckham, Evaluation of slip in capillary extrusion of ceramic pastes. Journal of the European Ceramic Society, 2001. 21(4): p. 483-491.

14. Yang, H.Y., et al., Mechanical strength of extrusion freeformed calcium phosphate filaments. Journal of Materials Science-Materials in Medicine, 2010. 21(5): p. 1503-1510.

15. Lu, X.S., et al., Solvent-based paste extrusion solid freeforming. Journal of the European Ceramic Society, 2010. 30(1): p. 1-10.

16. Lee, Y., et al., Directive millimetre-wave antenna based on freeformed woodpile EBG structure. Electronics Letters, 2007. 43(4): p. 195-196.

17. Lu, X.S., et al., Fabrication of Millimeter-Wave Electromagnetic Bandgap Crystals Using Microwave Dielectric Powders. Journal of the American Ceramic Society, 2009. 92(2): p. 371-378. 